\title{
DIALOGISMO NAS MENSAGENS DIRECIONADAS AOS PROFESSORES DE ESPANHOL EM MATERIAIS DIDÁTICOS DO SÉCULO XX E XXI: RUPTURAS E CONTINUIDADES
}

\author{
DIALOGISM IN MESSAGES ADDRESSED TO TEACHERS OF \\ SPANISH IN DYNAMIC MATERIALS OF THE XX AND XXI \\ CENTURY: RUPTURES AND CONTINUITIES
}

\author{
Diego José Alves Alexandre* \\ Pedro Farias Francelino*
}

\begin{abstract}
Resumo: Considerando o dialogismo como elemento constitutivo da linguagem (BAKHTIN/VOLOCHÍNOV, 2004), este estudo objetiva analisar as relações dialógicas nas mensagens destinadas aos professores de espanhol em livros didáticos de duas diferentes décadas: a de 1940, considerada o boom das produções didáticas de espanhol no Brasil pós-reforma de Capanema, e 2010, contexto em que o espanhol foi incluído nos editais de avaliação e publicação de livros didáticos no país. Nos resultados, nota-se que as obras recentes guardam relações dialógicas com a contemporaneidade e com o século anterior, fato que caracteriza e constitui o ensino de língua espanhola na atualidade.
\end{abstract}

Palavras-chave: Dialogismo. Ensino de espanhol. Material didático.

\begin{abstract}
Considering dialogism as a constitutive element of language (BAKHTIN / VOLOCHÍNOV, 2004), this study aims to analyze the dialogical relations in the messages destined to Spanish teachers in textbooks of two different decades: that of 1940, considered the boom of didactic productions of Spanish in Brazil after the Capanema Reform, and 2010, a context in which Spanish was included in a program for the evaluation and publication of textbooks in the country. In the results, it is possible to notice the recent books that maintain relations of dialogism with the contemporaneity and with the previous century, fact that characterizes and constitutes the teaching of Spanish language in the present time.
\end{abstract}

Keywords: Dialogism. Teaching Spanish. Didactic Material.

\section{Introdução}

De maneira geral, é consenso dizer que as duas últimas décadas no Brasil foram de significativo crescimento da língua espanhola, tanto no âmbito político-econômico, quanto no de políticas educativas para a valorização desse idioma e de seu ensino no contexto formal. Com a assinatura do Tratado de Assunção, em 1991, que resultou no acordo do MERCOSUL (Mercado Comum do Sul), o discurso de que "não basta o portunhol" retratou parte da opinião pública e reforçou a ideia de que o "momento é bom para as escolas de espanhol" 2 . Com isso, o mercado privado se apropriou de boa fatia dessa nova demanda e, ainda na primeira metade dos anos 90, fomentou a criação de escolas de língua espanhola ou a implantação desse idioma em cursos já existentes.

Em 1996 é elaborada a atual Lei de Diretrizes e Bases da Educação Nacional (LDB/96). O documento aborda a questão do plurilinguismo e sugere à comunidade

\footnotetext{
*Doutorando em linguística e professor do curso de Letras Espanhol da Universidade Federal do Rio Grande do Norte, na área de Didática e Ensino de Espanhol. diegojalexandre@ gmail.com

*Doutor em linguística e professor do curso de Letras da Universidade Federal da Paraíba e do Programa de Pós-graduação em Linguística da UFPB, na área de Análise Dialógica do Discurso. pedrofrancelino@yahoo.com.br

${ }^{1}$ Afirmação analisada por Celada (2002), em sua tese de doutorado, extraída da revista Mercosul. Revista de negócios. Mercado do Cone Sul. Ano II, n. 17, p. 66.

${ }^{2}$ Texto publicado pela Folha de São Paulo em 23 de outubro de 1994. Disponível em < http://www1.folha.uol.com.br/fsp/1994/10/23/tudo/1.html .
} 
escolar a escolha de mais de uma língua estrangeira. De acordo com Paraquett (2009), é nesse momento que muitas escolas privadas adotam o espanhol em seus programas, em alguns casos até como uma "estratégia de marketing, uma língua "diferente" (p. 126). Isso trouxe, no início dos anos 2000, já no século XXI, de acordo com Cassiano (2007, p.132), condições favoráveis para a ratificação da entrada de capital espanhol no Brasil, através de diversos segmentos, como o de "telefonia (Telefônica), energia elétrica (Endesa e Iberdrola), financeiro (banco Santander) e hoteleiro (Sol Meliá)".

Em agosto de 2005, a lei 11.161 foi promulgada. Com ela a oferta do espanhol passava a ser obrigatória por parte das escolas de ensino médio e, por parte dos alunos, facultativa a matrícula. A despeito dos problemas da dubiedade da sua redação e do seu efetivo cumprimento, a lei do espanhol e a LDB/96 sedimentaram bases que sustentaram a produção de documentos para a orientação do trabalho pedagógico em língua estrangeira, como é o caso dos Parâmetros Curriculares Nacionais, os PCN (BRASIL, 1998), e as Orientações Curriculares para o Ensino Médio (BRASIL, 2006). Todas essas políticas, pertencentes à esfera pública e aqui materializadas em documentos oficiais, direta ou indiretamente, promoveram a incorporação do espanhol ao Programa Nacional do Livro Didático (PNLD) ${ }^{3}$.

Essa incorporação do espanhol como língua estrangeira no PNLD representou uma nova guinada para essa língua na escola brasileira: além de esse passo representar o castelhano ${ }^{4}$ dentro do sistema educativo também por meio de materiais didáticos, as balizas estabelecidas para a produção desses livros passaram a ser elaboradas pelas instituições de ensino superior, instâncias essas marcadamente norteadas pela concepção de língua como uma atividade social, política e discursiva. Assim, percebemos que a fatia recente e exitosa da história do espanhol no Brasil não existiu sem políticas oficiais e que, nesse cenário, os livros didáticos atuaram como divisores de águas entre a lei e a legitimação da lei, embora não sem problemas e falhas.

No entanto, vale dizer que a trajetória do espanhol não está situada somente entre o MERCOSUL e o presente momento ${ }^{5}$. Mirando sua história no Brasil na primeira metade do século XX, já notamos intentos e ações concretas para que essa língua se tornasse oficial dentro da escola pública. Apesar de aqui, por uma questão de espaço, não detalharmos a gênese desse processo, nesse período cabe o destaque para a criação da cátedra de língua espanhola do Colégio Pedro II, em $1919^{6}$, que viria a ser ocupada

\footnotetext{
${ }^{3}$ A esse respeito, importante dizer que o PNLD é um programa do Ministério da Educação que, via edital, avalia e seleciona livros didáticos de diversas áreas do conhecimento para sua posterior distribuição entre os alunos das escolas públicas. Cassiano (2007) aponta que esse programa, embora criado em 1937 e reformado em 1985, só em 1995 se democratiza e se universaliza. O primeiro edital em que o espanhol foi contemplado, juntamente com o inglês, foi o de 2007 - com distribuição de livros em 2010 -, fato que, sem dúvida e como já apontado, é consequência da lei 11.161/2005.

${ }^{4}$ Neste artigo, não tocaremos nas discussões acerca da denominação espanhol e castelhano. Com efeito, trataremos essas palavras como sinônimas.

${ }^{5}$ Apesar de todos os movimentos em favor do espanhol até então narrados, atualmente essa língua se encontra, por assim dizer, desoficializada. Através da Reforma do Ensino Médio brasileiro (lei 13.415/2017), a lei do espanhol foi revogada. Consequentemente, ainda que seja cedo para análises e previsões, acredita-se em um arrefecimento de políticas para a formação de professores e de materiais didáticos nesse campo. Ainda assim, no entanto, a disciplina dentro do sistema educativo não foi extinta e incontáveis são os movimentos das associações de professores, organizados com as universidades públicas, para que a oferta do espanhol, pelo menos dentro dos sistemas municipais e estaduais de ensino, seja assegurada. É o caso, por exemplo, do estado da Paraíba, que promulgou, em 05 de setembro de 2018, a lei 11.191, tornando o espanhol como língua de oferta obrigatória dentro da sua rede estadual.

${ }^{6}$ A lei 3.674 de 07 de janeiro de 1919 especificou, em seu artigo segundo, valores para a criação da disciplina de língua espanhola no Colégio Pedro II.
} 
pelo filólogo Antenor Nascentes. Esse movimento político-educativo também gerou um movimento, por assim dizer, editorial, pois para ministrar espanhol no Pedro II, Nascentes elaborou a primeira gramática de língua espanhola no Brasil, a Grammatica da lingua espanhola para uso dos brasileiros, de 1920. Porém, apesar de sua importância histórica, esse passo representou um acontecimento isolado, justamente, talvez, por não ser fruto de uma política educativa mais ampla, o que só aconteceria duas décadas depois através da portaria ministerial 127, de 03 de fevereiro de 1943, consequência direta da Reforma de Capanema ${ }^{7}$.

A Reforma de Capanema fixou os conteúdos de espanhol a serem ministrados nos cursos clássicos e científicos do ensino secundário, fato que transformou os anos 40 do século passado em um período bastante rico quanto à produção editorial para o ensino do castelhano. Como na época a formação de professores de espanhol não era difundida, os materiais didáticos então elaborados pretendiam também dar conta dessa lacuna a partir de duas frentes: formar professores e atender metodologicamente os conteúdos fixados pelo governo federal. Assim, não raro encontrar nessas produções pequenos textos endereçados aos professores de espanhol que iriam utilizar aquele material. Mais tarde encontraríamos essas mesmas "conversas" com os docentes materializada em manuais do professor, elemento que, hoje, através dos critérios de avaliação do PNLD, é de presença obrigatória em qualquer coleção impressa via programa do livro didático.

Isso posto, dado que a história do espanhol é marcadamente pautada por políticas públicas e, nesse cenário, o livro didático ocupa importante papel na legitimação e nas "respostas" a essas políticas, nosso interesse reside em analisar as orientações/mensagens deixadas aos professores de espanhol nos materiais didáticos de ontem e de hoje. Para tanto, analisaremos quatro obras: duas publicadas na década de 1940 do século XX, pós-portaria ministerial que oficializou o espanhol no ensino secundário, e duas publicadas a partir do PNLD, precisamente no ano de 2016.

Acreditamos que as ações para o fortalecimento da língua espanhola através de materiais didáticos, em cada período supracitado, deixam afirmações linguísticodiscursivas essenciais para a compreensão de nosso atual estágio de discussão sobre ensino-aprendizagem, além de marcadamente apontar diálogos entre consciências, ou mesmo a presença das palavras do outro nas palavras do eu (BAKHTIN/VOLOCHÍNOV, 2004) inseridas em distintos períodos socioculturais.

Nosso objetivo, então, é analisar como as mensagens endereçadas aos professores, nas distintas produções didáticas e em cada época retratada, estabelecem relações dialógicas. Mais especificamente, pretendemos entender a natureza dessas relações e identificar, discursivamente, suas rupturas e permanências.

Como já antecipado no parágrafo anterior, nosso arcabouço teórico filia-se à Teoria/Análise Dialógica da Linguagem depreendida dos escritos de Bakhtin e o Círculo. Nesse sentido, vale fixar como pressuposto geral o fato de que neste trabalho o olhar se afastará de uma vertente estritamente estrutural e privilegiará a língua como instância da interação humana contextualmente (e por isso mesmo socialmente) situada. É o que abordaremos na seção a seguir.

\section{Dialogismo de Bakhtin/Volochínov}

\footnotetext{
${ }^{7}$ A Reforma de Capanema foi realizada no Brasil durante o período da Era Vargas (1930-1945), pelo então ministro da educação Gustavo Capanema.
} 
Um dos mais importantes pontos de partida para se compreenderem alguns conceitos básicos da Teoria/Análise dialógica se encontra em Marxismo e Filosofia da Linguagem ([1929]2004), de Bakhtin/Volochínov ${ }^{8}$. Para fundamentar a concepção de língua que subjaz a obra, rejeita-se tanto o subjetivismo idealista de Humboldt, Vossler e Spitzer, que apostava na fala individual como determinadora da realidade linguística, como também o objetivismo abstrato, que, representado por Ferdinand de Saussure, via a língua como um objeto imanente e autônomo. Sobre isso, Bakhtin/Volochínov (2004) afirmam:

A verdadeira substância da língua não é constituída por um sistema abstrato de formas linguísticas nem pela enunciação monológica isolada, nem pelo ato psicofisiológico de sua produção, mas pelo fenômeno social da interação verbal, realizada através da enunciação ou das enunciações. A enunciação verbal constitui assim a realidade fundamental da língua (BAKHTIN/VOLOCHÍNOV, 2004, p. 123).

Desse modo, para os autores, a língua constitui parte da comunicação verbal concreta e é historicamente situada. Isso significa que nem o sistema linguístico abstrato, nem o psiquismo individual dos falantes dão conta da complexidade envolvida na interação entre os indivíduos, a qual, por sua vez, estabelece a relação sujeitosociedade como sustentáculo da natureza dialógica da linguagem. A língua, nesse sentido, é um produto inacabado e envolto no fluxo da interação verbal. Apesar de considerar, assim como Saussure, a língua como um fato social, Bakhtin/Volochínov vão na contramão dos estruturalistas por acreditar que esta não é um si stema homogêneo e que as manifestações individuais, como a fala e a enunciação, estão ligadas às condições de produção. Portanto, há uma nuance na concepção de "social" desses autores, que vão mais além do aspecto de "coletividade" defendido por Saussure.

É por isso que todo o enunciado é um elo na cadeia da comunicação discursiva e representa o resultado de uma posição ativa do falante numa dada realidade concreta. Assim, o ato de enunciar não se concretiza pela escolha de palavras ou de uma forma neutra, mas a partir de outros enunciados já proferidos. Além disso, a enunciação é social e só adquire esse estatuto quando da interação entre os indivíduos: a palavra parte de alguém e se dirige a alguém. Portanto, toda enunciação é dialógica, seja ela oral ou escrita, e confere ao "diálogo" um sentido amplo, ou seja, "não apenas com a comunicação em voz alta, de pessoas colocadas face a face, mas toda a comunicação verbal, de qualquer tipo que seja”. (BAKHTIN/VOLOCHÍNOV, 2004, p. 123).

Os enunciados produzidos em nossas interações sociais, os quais provêm da nossa experiência discursiva constituída em meio às mais diversas relações alteritárias, apresentam ecos e ressonâncias de discursos alheios com os quais mantemos algum tipo de reação responsiva ativa, ou seja, relações de concordância, discordância, refutação, aplicação etc. Ressaltamos, no entanto, que há uma dinâmica de apropriação do discurso de outrem, de modo que ele integra nosso discurso a serviço de uma intenção, de um propósito discursivo definido. Preparamos para ele uma moldura dialógica, atribuímos a ele, em determinado contexto enunciativo, um acento e uma tonalidade valorativos.

Nesse sentido, os enunciados não apenas se reportam a outro(s) de forma fortuita, mas se submetem ou se subjugam à intenção discursiva de um enunciador que lhes confere uma nova coloração. Convém afirmar que, mesmo que um enunciado seja convocado para outro contexto, com a maior precisão possível, estará impregnado das

\footnotetext{
${ }^{8}$ Por falta de espaço e por não configurar uma questão central deste trabalho, aqui não faremos discussões sobre a autoria das obras advindas do Círculo de Bakhtin.
} 
intenções, do acento e das expressões do seu segundo senhor.

Para Bakhtin, não há primeira nem última palavra quando falamos em contexto dialógico, pois os sentidos do passado jamais serão acabados (finalizados ou concluídos), antes, em qualquer momento, poderão ser convocados e, por consequência, atualizados. O enunciado é um participante do diálogo social, uma vez que

O enunciado existente, surgido de maneira significativa num determinado momento social e histórico, não pode deixar de tocar os milhares de fios dialógicos existentes, tecidos pela consciência ideológica em torno de um dado objeto de enunciação, não pode deixar de ser participante ativo do diálogo social. Ele também surge desse diálogo como seu prolongamento, como sua réplica, e não sabe de que lado ele se aproxima desse objeto. (BAKHTIN, [1895-1975] 1993, p. 86).

Nessa perspectiva, um objeto do discurso apresenta-se sempre envolto por pontos de vista de outrem, impregnado de apreciações valorativas, embebido, cercado por discursos outros com os quais estabelece relações dialógicas (de sentidos, portanto) diversas. Assim, para constituir nosso discurso, levamos em consideração a cosmovisão de mundo de nossos interlocutores, do passado e/ou do presente, de modo que nossos enunciados refratarão, inevitavelmente, a posição axiológica à qual se reportam.

Relacionando esses pressupostos ao corpus investigado na presente pesquisa, interessante notar que os recados deixados aos professores, seja em obras escritas nos anos 40 do século XX, seja em obras dos anos 10 do século XXI, carregam consigo os contextos históricos em que foram produzidos. As primeiras obras, mais antigas, surgiram a partir de reformas do ensino secundário brasileiro e da fixação de conteúdos básicos de espanhol que a escola deveria contemplar. As posteriores, mais recentes, obedecem a critérios de publicação advindos de um programa nacional de seleção de livros didáticos. Ambas as séries se dirigem à aprendizagem da língua espanhola e, especificamente no nosso trato analítico, ao professor dessa língua. Assim, tudo dito nesses materiais guarda em si relações dialógicas com outros discursos anteriores e contemporâneos (que por sua vez se relacionam aos anteriores, num ciclo): o diálogo é travado entre as décadas e reflete e refrata um tempo, um discurso, uma visão sobre o ensino de espanhol como língua estrangeira no Brasil.

Ainda conforme Bakhtin (1998), pode-se dizer que o enunciado está repleto de ecos de outros enunciados e estes devem ser considerados, sobretudo, como uma resposta a enunciados anteriores dentro de uma dada esfera. Refutamos, concordamos, rejeitamos, completamos enunciados diante de nós no momento em que lemos, como docentes de espanhol, uma curta seção inicial que nos endereça uma mensagem de recomendações didáticas, ou até mesmo um manual do professor, contida em um livro didático.

Nessa perspectiva, para Bakhtin/Volochínov (2004), a interlocução ocupa papel importante no diálogo justamente por o falante, em qualquer uma das extremidades desse colóquio, constituir uma "ponta" ativa e capaz de se envolver e de interagir com e sobre o outro. Portanto, a interlocução com os possíveis leitores das obras determina a estrutura da interlocução: na elaboração do enunciado, no caso as mensagens destinadas aos futuros professores, ou seja, os manuseadores das obras didáticas em questão, há uma orientação tanto para o já-dito como para o que se está por dizer. 
A pressuposição desse interlocutor, considerando o que os estudiosos russos chamaram de horizonte social, é determinante para fixar o que se quer dizer e como fazê-lo. Assim sendo, Bakhtin/Volochínov dispõem uma ordem metodológica sobre como o analista deve estudar a língua. Na ordem que segue, devem-se pontuar:

1. As formas e os tipos de interação verbal em ligação com as condições concretas em que se realiza.

2. As formas das distintas enunciações, dos atos de fala isolados, em ligação estreita com a interação de que constituem os elementos, isto é, as categorias de atos de fala na vida e na criação ideológica que se prestam a uma determinação pela interação verbal.

3. A partir daí, exame das formas da língua e sua interpretação linguística habitual (BAKHTIN/VOLOCHÍNOV, 2004, p. 124).

Neste trabalho, no tocante à análise dos dados, seguimos esses encaminhamentos teórico-metodológicos. Destacamos, previamente, a constituição do nosso corpus. Como já dito, trata-se de quatro obras didáticas: duas publicadas na década de 1940, de quando aconteceu o boom dessas produções para o ensino de espanhol, consequência direta da Portaria Ministerial 127; e mais duas da década de 2010, consequência da inclusão do espanhol no PNLD, que por sua vez só aconteceu após a promulgação da Lei 11.161/2005. Seguem os dados:

Quadro 1 - descrição do Corpus

\begin{tabular}{|c|c|c|c|c|c|}
\hline Livros & Autor(es) & Parte Analisada & Ano de public./ediçãa & Editora & $\begin{array}{c}\text { Como } \\
\text { citamos }\end{array}$ \\
\hline $\begin{array}{l}\text { Nociones de } \\
\text { Gramática } \\
\text { Española }\end{array}$ & $\begin{array}{c}\text { José } \\
\text { Hernández }\end{array}$ & Mensagem inicial & $1946,1^{a}$ ed. & Anchieta & L1 \\
\hline $\begin{array}{l}\text { Gramática } \\
\text { Castellana }\end{array}$ & $\begin{array}{c}\text { Raul G. } \\
\text { Lagomarsino }\end{array}$ & Mensagem inicial & $1949,2^{\mathrm{a}}$ ed. & A nação & L2 \\
\hline $\begin{array}{c}\text { Cercanía } \\
\text { Joven } \\
\text { vol. } 1\end{array}$ & $\begin{array}{l}\text { Ana Luiza } \\
\text { Couto, } \\
\text { Ludmila } \\
\text { Coimbra e } \\
\text { Luíza } \\
\text { Santana } \\
\text { Chaves }\end{array}$ & $\begin{array}{l}\text { Introdução do } \\
\text { Manual do } \\
\text { Professor }\end{array}$ & $2016,2^{\mathrm{a}}$ ed. & SM & L3 \\
\hline $\begin{array}{c}\text { Sentidos en } \\
\text { lengua } \\
\text { española } \\
\text { vol. } 1\end{array}$ & $\begin{array}{c}\text { Luciana } \\
\text { Maria A. de } \\
\text { Freitas e } \\
\text { Elzimar G. } \\
\text { de Marins } \\
\text { Costa. }\end{array}$ & $\begin{array}{l}\text { Introdução do } \\
\text { Manual do } \\
\text { Professor }\end{array}$ & $2016,1^{a}$ ed. & $\begin{array}{c}\text { Richmon } \\
\mathrm{d}\end{array}$ & L4 \\
\hline
\end{tabular}

Fonte: dados da pesquisa

Isso posto, analisamos as relações dialógicas entre os enunciados dos livros em tela, especificamente no que se refere às mensagens deixadas diretamente aos professores que manuseariam as obras. Não nos deteremos novamente na contextualização de cada período, uma vez que, para os objetivos traçados e para o espaço de que dispomos neste artigo, o que construímos até então parece suficiente. Passemos à análise dos dados.

\section{Análise dos dados}


Nas análises que agora teceremos, o interesse reside em compreender as relações dialógicas constantes nas apresentações dos livros, ora confrontando as produções, ora as mirando em seus contextos de produção, e com isso dando espaço às várias vozes sociais que as constituem e engendram sentidos. Para escolhermos os fragmentos apresentados, levamos em conta quais englobavam o discurso sobre o professor e sua prática, a relação dos materiais com documentos oficiais e a visão sobre a língua espanhola dentro da escola brasileira. Esses aspectos, a nosso ver, merecem relevo porque à medida que sublinham ideias sobre a língua, tecem discursos que reverberam até a atualidade.

Para iniciar a análise, trazemos a seção intitulada "Aos professores", momento em que L1 é apresentado aos seus primeiros usuários, os professores de espanhol:

(L1) Ao apresentarmos a nossos colegas estas noções de língua castelhana, fazemo-
lo com o único intuito de tornar prático o estudo desta disciplina em nossos colégios
(...)
O professor ao iniciar seu curso deverá preferir textos modernos, portanto os últimos
da Antologia (...). No início, é de grande proveito que o aluno decore algumas
poesias, para não só exercitar-se na pronúncia e melodia castelhana, mas também
aprender rapidamente algumas particularidades (...)
Feita a leitura, segue-se a explicação de trechos poéticos, se for o caso (...). Outro
princípio importante é jamais separar a explicação literária do estado social
correspondente (...). (HERNÁNDEZ, 1946, p. 5-6)

De início, chamamos a atenção para a construção "a nossos colegas", que firma uma ideia de aproximação aos professores da educação básica que iriam utilizar o livro: o autor se coloca também como professor. Interessante notar que a iniciativa se repete em L2, publicado quatro anos depois de L1, mediante a construção "Aos Srs. Professores". L3 não se dirige, por vocativo, a ninguém. L4, por sua vez, utiliza-se de "professor/professora". Essas formas de tratamento dadas ao profissional de educação, em cada tempo, mostra a tentativa de aproximação entre as obras didáticas e os seus agentes utilizadores - e por isso um sujeito essencial para o funcionamento daquele produto, o livro. Além disso, se no passado a formalidade com que se dirigia ao professor era um aspecto corriqueiro, atualmente, como visto em L4, sobressai-se a pluralidade: desde há muito que mulheres também fazem carreira na docência. Esta, assim, é outra aproximação pretendida: o discurso do gênero, tão contemporâneo, está atravessado pelo discurso pedagógico (e vice-versa) presente nos materiais didáticos da atualidade.

Isso significa que, como qualquer produto construído socialmente, as mensagens deixadas aos professores, em diferentes décadas, refletem e refratam uma realidade, que lhe é exterior (BAKHTIN/VOLOCHÍNOV, 2004). Isso tem a ver, também, com a maneira como se sugeria/se sugere a conduta do profissional da educação. Como transcrito no excerto acima, trechos de L1 estão repletos de verbos no imperativo, que praticamente direcionam os passos metodológicos que devem ser dados dentro da sala de aula. Interessante notar essa construção vinda justamente do autor, que considera seu público especializado como "colega" - fato que nos leva a crer que ideologias de outras esferas também atravessam a materialidade discursiva dessas mensagens, tensionado dizeres e contradizendo vozes. Além disso, palavras como "decorar" e "exercitar-se" dialogam com o discurso mecanicista ligado à educação - o 
que também reverbera nos papéis dos sujeitos (o professor e o aluno devem desempenhar posições muito bem delimitadas).

Por outro lado, vale o destaque para L4, que tenta garantir a relação de igualdade entre autores e professores de espanhol:

(L4) Se esta é uma conversa entre colegas, não pretendemos e nem podemos querer
"ensinar" algo a você. Talvez tenhamos informações e reflexões sobre alguns
aspectos do trabalho docente, mas você terá outras, igualmente ou até mais
importantes do que as nossas. Por exemplo, somente você conhece o seu contexto
educativo: sua escola, suas turmas, seus estudantes, sua comunidade (...). Portanto,
corremos o risco, inclusive, de sugerir uma série de pontos que, de acordo com sua
experiência, poderão ser obviedades. (FREITAS e COSTA, 2016, p. 163).

O trecho acima é um claro estabelecimento anti-hierárquico entre autores e professores. Por ser ali estabelecido um virtual diálogo com um também docente, há o estabelecimento de que não se pretende "ensinar" a quem, supostamente, já sabe, e a proposta então pauta-se no compartilhamento de saberes. O discurso de L4, portanto, está ligado a uma orientação discursiva da atualidade que pretende horizontalizar a relação entre quem produz material (especialistas renomados, acadêmicos etc.) e quem o utiliza para ministrar aulas.

Ainda sob esse prisma, é notório que na década de 1940, apesar das flagrantes contradições quanto a esse aspecto, também se levava em conta que, sem o docente e o seu retorno intelectual, baseado em sua experiência, as obras didáticas resultariam obsoletas. Isso se afina tanto em L1 quanto em L2, como se observa nos trechos que seguem:

(L1) Agradecemos qualquer crítica construtiva a ser feita a êste despretensioso livrinho como também a atenção de que nossos prezados e cultos colegas recebermos (HERNÁNDEZ, 1946, p. 7).

(L2) (...) confio ao bom critério e prática didática dos Srs. Professores e aproveitamento do material literário inserido ao fim de cada capítulo (...)

Solicito com particular empenho dos meus bons e dedicados colegas, queiram indicar senões ou defeitos, falhas ou excessos - desculpando e apontando qualquer êrro que por infelicidade haja escapado às revisões feitas (LAGOMARSINO, 1949, p. 6).

Como na atualidade, percebe-se nesses trechos a figura do professor como detentora de valiosas experiências e que, num trabalho colaborativo, aperfeiçoará os livros então publicados. Não à toa essa relação horizontal foi e é ainda hoje perseguida pelos autores: os professores, numa ampla gama de opções, são os que escolhem os livros para o exercício do magistério - ou seja, o autor em questão, aquele que faz "despretensioso livrinho", precisa dos professores. Em L2 isso fica bastante evidente: 
(L2) Nas primeiras páginas inserimos o programa de Espanhol proposto pelo Ministério da Educação e Saúde ao regulamentar o estudo desta disciplina. Os Srs. Professores que porventura julgarem conveniente adotar êste livro, extrairão dêle o que estimar adequado para satisfazer o dito programa (LAGOMARSINO, 1949, p. 6 , grifo do autor).

Isso quer dizer que, por mais que exista a tentativa de "igualar o nível" entre os autores e os professores, por trás da forma tratamento, também se evocam estratégias de persuasão, que no trecho acima se guia pelo programa de espanhol fixado pela Reforma de Capanema, ou seja, uma política educativa e linguística. Desse modo, descortina-se o entrelaçamento, nessas produções, entre o discurso pedagógico e o discurso mercadológico.

Outro aspecto analisado tem a ver com os documentos oficiais/legislações que regularam o contexto de produção das obras. Das quatro, as mais recentes fazem menção, dentro do manual destinado ao professor, a documentos que regem o currículo da educação básica, como os PCN, as OCEM (consequência direta da lei 11.161/2005) e a LDB. Entre as obras mais antigas, apenas L2 referencia a portaria ministerial número 127, que fixou os conteúdos de língua espanhola no ensino secundário do Brasil. Essa portaria, juntamente com o programa de espanhol dos cursos clássico e científico, está impressa já nas primeiras páginas. Desse modo, a referida explicitude espelha o contexto externo à obra e pretende conferir ao material a legitimidade para sua venda, para a sua divulgação entre os professores, os primeiros a adotarem o material, como já sinalizado.

A sua vez, os livros mais contemporâneos revelam claramente os documentos oficiais para o ensino de língua estrangeira, seja dentro da introdução do manual do professor, seja diluído em todo esse material - à diferença das obras dos anos 40. Isso porque, citar leis para a educação (sobretudo a educação linguística) é critério eliminatório para a aprovação dos livros no Programa Nacional do livro Didático. No guia PNLD do ano de 2018, no que diz respeito ao manual do professor, a avaliação das obras, entre outras questões, verifica se a coleção "2. Relaciona a proposta didática da obra aos documentos organizadores e norteadores do Ensino Médio, no que se refere às línguas estrangeiras" (BRASIL, 2017, p. 18).

Quanto a esse aspecto, L4 o concretiza em todo o manual destinado ao professor. Apesar de o manual, como um todo, não fazer parte do nosso recorte analítico aqui empreendido, é necessário considerar a seção "Nossa coleção e os documentos norteadores da Educação Brasileira" dentro dessa obra, já que é uma referência direta aos critérios de avaliação do PNLD:

(L4) A proposta teórico-metodológica da coleção reforça o caráter educativo da língua estrangeira na Educação Básica, indo ao encontro do indicado nos documentos que até bem pouco tempo norteavam a educação e apresentavam seções específicas para a disciplina de Língua Estrangeira, tais como os Parâmetros Curriculares Nacionais - PCN (BRASIL/SEF, 1998) e as Orientações Curriculares para o Ensino Médio - OCEM (BRASIL/SEMTEC, 2006), este último também com uma seção para Espanhol. (FREITAS e COSTA, 2016, p. 168).

A citação acima, por mais que pareça apenas cumprir o quadro de avaliação do Programa do Livro Didático, está amarrada ao contexto e, além de refleti-lo, também o refrata (BAKHTIN/VOLOCHÍNOV, 2004). Isso porque as autoras fazem algumas ressalvas sobre a validade dos documentos oficiais que citam inicialmente e, para tanto, 
empregam verbos no passado ("indo ao encontro do indicado nos documentos que até bem pouco tempo norteavam a educação e apresentavam seções específicas para a disciplina de Língua Estrangeira"). Isto é: apesar de considerar os PCN e as OCEM como documentos norteadores da educação básica, as autoras os colocam com menos legitimidade, já que, na época da escrita de L4, havia a grande discussão em torno da elaboração da Base Nacional Curricular Comum (BNCC), e que, portanto, ainda não estava pronta ${ }^{9}$. Consideremos mais um excerto em que isso é ilustrado:

(L4) No momento em que escrevemos esta coleção, não há documento, como eram os PCN e as OCEM, dirigido às especificidades de cada componente curricular da Educação Básica (FREITAS e COSTA, 2016, p. 168).

Essa constatação remonta a palavras de Bakhtin/Volochínov, especificamente quando trata do livro como ato de fala impresso: o livro didático também se constrói na interação e por isso mesmo notadamente direcionado a um interlocutor: "Assim, o discurso escrito é de certa maneira parte integrante de uma discussão ideológica em grande escala: ele responde alguma coisa, refuta, confirma, antecipa as respostas e objeções potenciais, procura apoio, etc." (BAKHTIN, 2004, p. 123).

L3 vai nesse sentido quando utiliza citações dos documentos oficiais para argumentar a favor do espanhol na escola básica brasileira:

(L3) Más que asumir un carácter informativo, la esencia del aprendizaje de Español en la escuela básica es el desarrollo de la ciudadanía: "O estudo da língua estrangeira permite a reflexão sobre o idioma e a cultura como bens de cidadania" (PCN+ Ensino Médio, 2002, p. 101). (COUTO, COIMBRA e CHAVES, 2016, p. 181 , grifo das autoras).

As autoras usam um documento norteador para ratificar o argumento sobre a necessária presença do espanhol na escola. Desse modo, contempla-se parte do edital do PNLD e atende-se a demandas discursivas. Mais: no e pelo discurso, legitima-se a obra didática em questão e a língua estrangeira como disciplina obrigatória, bem como o seu papel na escola brasileira. Ademais, essa visão, ao passo em que desencadeia afirmações sobre a língua no sistema educativo, paralelamente descortina ideias sobre o próprio objeto em tela: o espanhol.

Interessante notar que não nos parece necessariamente uma novidade o livro L3, na parte introdutória do manual do professor, afirmar que a obra propõe:

(L3) Un abordaje interactivo, que valora conocimientos previos y las vivencias de los alumnos para, a la vez, insertarlos en un nuevo panorama de conocimientos sociales, artísticos y discursivos (...) (COUTO, COIMBRA e CHAVES, 2016, p. 181).

Essa não-novidade dentro dos manuais do professor no tocante à valorização dos conhecimentos prévios dos alunos como um guia para as aulas a serem ministradas pelo docente é reflexo, mais uma vez, dos documentos oficiais contemporâneos ou de

\footnotetext{
${ }^{9}$ Não discutiremos aqui os problemas estruturais e político-educativos da BNCC, homologada em 20 de dezembro de 2017. Apenas contextualizamos as razões para a ressalva das autoras.
} 
data mais ou menos próxima à publicação de L3. Também é reflexo, sobretudo, da mudança na forma como enxergamos a relação professor-aluno. Por outro lado, para nós, a novidade reside no fato de que 70 anos antes essa preocupação já existia e já se figurava em mensagens aos professores. É o que vemos em L1:

(L1) A redação terá como fontes o vocabulário e as construções sintáticas da Antologia e como inspiração fatos da vida dos alunos, concretizando-se sempre numa novela em capítulos, escrita semanalmente por um novo aluno (HERNÁNDEZ, 1946, p. 5).

A inspiração nos fatos da vida dos alunos revela que o conhecimento prévio, para o autor de L1, é fundamental para uma boa aula de espanhol. Ou seja, os conhecimentos prévios dos estudantes também servem de guia para a prática docente, como seria, hoje, tão apregoado nas recomendações oficiais e nos próprios livros didáticos para o exercício do magistério.

Desse modo, o atravessar dos anos nos revela, dialogicamente, que no ontem e no hoje, as aulas deveriam partir da interação efetiva entre docentes e discentes. Apesar de na década de 1940 essa ideia talvez não estivesse, a partir do senso comum, arraigada entre as escolas e entre os profissionais da educação, o autor de L1 propõe um modelo diferente para a escola básica, modelo no qual a interação faz toda a diferença (inclusive para o uso do livro). Isso se repete em 2016, então reformulado por "un abordaje interactivo". As interpretações para cada afirmação, no entanto, obedecem a contextos e sujeitos sociais distintos: "É nisso que reside a vida da obra ideológica. Em cada época da sua existência histórica, a obra é levada a estabelecer contatos estreitos com a ideologia cambiante do cotidiano, a impregnar-se dela, a alimentar-se da seiva nova secretada" (BAKHTIN/VOLOCHÍNOV, 2004, p. 119).

Nesse sentido, salutar discutir a ideia que se tem sobre a língua espanhola estritamente falando, o que, obviamente, determina como ensiná-la na escola.

(L1) O aluno poderá dentro de pouco tempo estar escrevendo em espanhol se tomar conhecimento das normas gramaticais e ler continuadamente textos (HERNÁNDEZ, 1946, p. 5).

(L2) Desejo fazer notar que o critério adotado foi o de estudar a língua castelhana tal como ela é (...) Entretanto, como se trata de uma obra escrita para estudantes brasileiros - muitos aptos, em geral, para em curto prazo ler e traduzir o idioma espanhol - aproveitei esta circunstância para fazê-lo na língua em apreço procurando facilitar a compreensão dos alunos com a simplicidade da linguagem empregada e a tradução imediata para o português dos termos habitualmente usados em Gramática e dos vocábulos e frases dados como exemplo (LAGOMARSINO, 1949 , p. 6, grifo do autor).

(L3) La obra procura contribuir de manera efectiva no solo para la adquisición lingüística y cultural del español como lengua extranjera, sino también para que los sujetos del proceso de enseñanza y aprendizaje, profesores y alumnos, seamos igualmente ciudadanos más autónomos, críticos, creativos y participantes. En este sentido, se proporciona el contacto socio-lingüístico-cultural con los pueblos hispanohablantes y se relaciona el aprendizaje de la lengua española con otros conocimientos, modos de pensar y actuar en la vida (...) En fin, ser profesor de español en Brasil significa, sobre todo, saber que las Lenguas Extranjeras en las escuelas regulares brasileñas de enseñanza básica cumplen una función social 
O contraste entre as duas primeiras citações e a última revela diferenças que extrapolam os distintos anos de publicação de cada livro. De um lado, L1 e L2 entendem a língua espanhola e seu ensino a partir da gramática, o que, na visão dos autores, sobretudo o de L2, significa a língua tal como ela é. Aliado a isso, a tradução parece uma técnica bastante acertada, inclusive pela suposta proximidade entre os idiomas castelhano e português. Apesar dos problemas que essa suposta semelhança entre as línguas acarreta para o ensino desse idioma estrangeiro no Brasil, para o espanhol, dentro do sistema educativo, isso representa um ensino instrumental e pouco reflexivo, nos moldes dos cursos livres. Em outra medida, L3 apresenta uma ideia de língua que ultrapassa a aquisição e pretende alcançar o aprendizado dessa língua como um degrau para a cidadania. Mais do que regras gramaticais, abarca-se o contato sóciolinguístico-cultural do espanhol e o povo que o fala - a dimensão social da língua.

Outro ponto que merece destaque nos dois primeiros excertos acima diz respeito à ideia de aprendizagem e rapidez, praticidade. Em L1 e em L2, a possibilidade de se aprender espanhol "dentro de pouco tempo", ou "para em curto prazo ler e traduzir o idioma espanhol" representa uma premissa que ecoa até os dias de hoje, sobretudo em propagandas para cursos livres de idiomas. Não raro encontrar, em outdoors espalhados pelas cidades ou até mesmo em comerciais de TV, cartazes e imagens que associam qualidade de aprendizagem a pouco tempo de estudo: a lógica, no ontem e no hoje, obedece a um discurso puramente comercial, o de que quanto menos tempo estudando, melhor os professores que ensinam e melhor o material que usam - concepção que, como vemos em L3, contraria a justificativa para a presença de línguas estrangeiras no sistema escolar.

Assim, percebemos que, de tanto diálogo estabelecido entre as obras de diferentes épocas, muitos são os ecos (in)visíveis. Mas sobre isso trataremos nas considerações finais.

\section{Considerações finais}

$\mathrm{Na}$ análise empreendida, percebemos pelo menos três aspectos analíticos: $a$ relação entre os autores e os professores de espanhol, bem como a consideração acerca da conduta destes em sala de aula; a referência a documentos oficiais elou legislação específica para o ensino do castelhano; e a visão sobre a língua espanhola e sua repercussão na maneira como a devemos ensinar na escola básica. Apesar de muitos outros possíveis, tais aspectos são salutares porque nos ajudam a entender a relação de ruptura/continuidade do ensino de espanhol sob a lente da atualidade.

Noutras palavras, pretendemos dizer que os materiais escritos, hoje, para o professor de espanhol, guardam relações com os materiais do "ontem". Isso significa que os autores atuais não são sujeitos concluídos que simplesmente hoje vivem no século XXI com isenção, mas que, em verdade, carregam consigo experiências discursivas de outrora, materializadas em textos orais e escritos. A tentativa de se aproximar do principal divulgador de seu trabalho, do indivíduo que põe "em funcionamento" um livro produzido por outrem, significa, também, uma estratégia persuasiva que, através do êxito (leia-se adoção de determinado $L D$ ), também garante um discurso sobre a língua e, consequentemente, sobre o ensino.

É claro que não se pode, nesse bojo, esquecer o contexto que determina a produção/recepção de cada mensagem destinada ao docente de espanhol aqui analisada. 
Enquanto hoje os autores de livros didáticos, além de possuírem formação específica para a elaboração desse produto educativo, também escrevem seus materiais com base em um edital, que por sua vez está afinado com concepções de língua como interação, os escritores de ontem o faziam baseados em poucas experiências acadêmicas (poucos ou nenhum tinha(m) formação em Letras ou áreas afins, por exemplo) e em um momento que a disciplina Linguística, tal qual como a concebemos hoje, não havia chegado às universidades.

Isso também vale para os documentos oficiais. Se hoje estamos rodeados por leis e materiais legais que norteiam o ensino de língua materna e estrangeira, os autores dos anos 40 tinham, até aquele momento, apenas os conteúdos de espanhol fixados pelo Ministério da Educação. De todo o modo, tanto ontem quanto hoje, o tratamento dado aos professores de espanhol, a clareza com que se citam documentos oficiais e a noção de língua e ensino de cada época revelam a tentativa de legitimação do material, ou seja, uma justificativa para a sua existência. E aí está a maior relação dialógica.

Assim, nesse quadro contemplativo/valorativo/comparativo, nota-se que as permanências e rupturas sobre esses e outros aspectos da produção de material didático de espanhol passam pelo crivo da dimensão sociocultural de cada época. Mais do que isso, as permanências e rupturas iluminam o caminho que hoje ainda trilhamos em relação à didática do espanhol: tensões ideológicas entre o ontem e o hoje, movimentos de (des)oficialização política e a desejada praticidade em confronto com a também desejada (e fundamental) formação de cidadãos.

\section{Referências}

BAKHTIN, M. Questões de literatura e estética (a teoria do Romance). São Paulo: Editora UNESP, 1998.

BAKHTIN, M./VOLOCHÍNOV, V. Marxismo e filosofia da linguagem. São Paulo: HUCITEC, 2004.

BRASIL. Lei no 3.674, de 7 de janeiro de 1919. Fixa a despeza geral da Republica dos Estados Unidos do Brasil para exercicio de 1919. Rio de Janeiro: MEC, 1919.

Portaria Ministerial 127, de 3 de fevereiro de 1943. Expede e determina a execução do programa de espanhol dos cursos clássicos e científicos do ensino secundário.

Orientações curriculares para o Ensino Médio: Linguagens, códigos e suas tecnologias. Brasília: Ministério da Educação, Secretaria de Educação Básica, v. 1. 2006.

PNLD 2018: espanhol - guia de livros didáticos - Ensino Médio/Ministério da Educação - Secretaria de Educação Básica - SEB - Fundo Nacional de Desenvolvimento da Educação. Brasília: Ministério da Educação, 2017.

CASSIANO, C. O mercado do livro didático no Brasil: da criação do programa do livro didático (PNLD) à entrada do capital internacional espanhol (1985-2007). São Paulo, 2007. Tese (Doutorado em linguística) PUC 
CELADA, M. T. O espanhol para o brasileiro: uma língua singularmente estrangeira. Campinas, 2002. 278f. Tese (Doutorado em linguística). Instituto de Estudos da linguagem, UNICAMP,

COUTO. A. L.; COIMBRA, L.; CHAVES, L. S. Cercanía joven. São Paulo: Editora SM, 2016.

FREITAS, L. M.; COSTA, E. G. Sentidos en lengua española. São Paulo: Richmond, 2016.

HERNÁNDEZ, J. Nociones de Gramática Española. São Paulo: Editora Anchieta, 1946.

LAGOMARSINO, R. G. Gramática Castellana. Porto Alegre: A Nação edições, 1949.

PARAQUETT, M. O papel que cumprimos os professores de espanhol como língua estrangeira (E/LE) no Brasil. Cadernos de Letras da UFF - Dossiê: Diálogos Interamericanos, Niterói, n. 38, p. 123-137, 2009.

Recebido em 26 de fevereiro de 2019

Aceito em 27 de abril de 2019 